\title{
TRIBOLOGICAL EFFECTS IN DEEP DRAWING OPERATION OF SUS304 BA
} STAINLESS STEEL SHEET

\author{
N. ANGSUSERANEE ${ }^{1}$, B. WATCHARASRESOMROENG ${ }^{2}$, P. BUNYAWANICHAKUL $^{3} \&$ S. $^{2}$ \\ CHARTNIYOM ${ }^{4}$ \\ ${ }^{1,3}$ Department of Mechanical Engineering, Faculty of Engineering, Srinakharinwirot University, Thailand \\ ${ }^{1,2}$ Tool and Die Technology Center (TDTC), Faulty of Engineering and Architecture, Rajamangala University of Technology \\ Suvarnabhumi, Thailand \\ ${ }^{4}$ Department of Industrial Engineering, Faculty of Engineering, Srinakharinwirot University, Thailand
}

\begin{abstract}
The objective of this article is to study the tribological properties that affect the deep drawing of SUS304 BA stainless steel. The tooling material is hardened SKD11 cold work tool steel. A tribometer was used to study the tribological properties between the contacting surfaces of the tooling material and the workpiece material. The study results were linked to the results of the deep drawing experiment. The study shows that lubricant can reduce the friction coefficient between the contacting surfaces of the hardened SKD11 tool material and SUS304 BA stainless steel by more than 6 times. The hardness of solid film can reduce the wear volume of tooling materials. However, the TiAlN-coated tool cannot deep draw SUS304 BA stainless steel while the hardened SKD11 tool can deep draw successfully at 131 cups for SUS304 BA stainless steel under dry conditions. DLC film helps improve the tribological properties between the contacting surfaces of the hardened SKD11 tool steel and SUS304 BA stainless steel and can also be used for deep drawing more than 1500 cups under dry conditions.
\end{abstract}

KEYWORDS: Tribology, Deep Drawing, Stainless Steel, SUS304

Received: Jun 09, 2020; Accepted: Jun 29, 2020; Published: Aug 03, 2020; Paper Id.: IJMPERDJUN2020591

\section{INTRODUCTION}

Deep drawing is the process of making sheet metal blanks into various hollow shapes and desired depths by plastic deformation mechanism in order to avoid sheet metal damage. The important tools for a deep drawing operation are the punch, die and blank holder. The punch begins to draw the sheet metal blank by sliding through the blank holder plate and die to form the sheet metal blank into the desired shape. The tribological properties between the contacting surfaces of the tools and sheet metal will play an important role in the success of the sheet metal forming, whether it is the shape of the workpiece, the quality of the surface, or the service life of the tools. Therefore, there are studies that are interested in researching the properties and increasing the tribological performance between the contacting surfaces of the tool and workpiece materials. Cold sheet metal forming typically uses lubricants to improve the tribological properties between the contacting surfaces of the die and sheet metal to reduce friction, wear, and forming forces [1]. However, lubricants are substances that are often harmful to the environment [2,3], and therefore efforts are made to avoid or reduce the amount of lubricants used in the metal forming process. 
Stainless steel is increasingly demanded for applications in corrosive environments. However, many studies [1, 48] have reported the severe problem of stainless steel transferring and adhering on the tool surface, especially when forming under non-lubricated or dry conditions. The use of a solid film coating on forming tools is one of the surface engineering techniques that is commonly used to solve the adhesion of workpiece materials and extend tool life. However, each type of solid film has a different tribological performance for use in forming with different materials [9-11].

DLC films have the performance to prevent adhesion of workpiece materials on the tool surface when forming aluminum alloy and stainless steel [3, 12]. However, when used for forming high strength steel and advanced high strength steel, the film peels off due to the low bonding strength of the DLC film and tool material [10]. Nitride-type solid films such as TiN have the performance in preventing adhesion when forming aluminum and titanium alloys [6], but when used for forming advanced high strength steel, adhesion was found on the workpiece material during the first forming with the TiN-coated tool [11].

The study of the tribological properties between the contacting surfaces of the tool and workpiece material in metal forming can be done in many ways, such as practical forming, simulation testing and numerical analysis [1, 3-13]. It is well known that practical forming results are quantitative and more empirical than simulation testing and numerical analysis. However, it is highly wasteful. Alternatively, simulation testing and numerical analysis can help with problem solving and declaring material performance for choosing process variables that will design the tool for forming appropriately.

From previous studies, there are many types of solid films to choose from in order to improve the tribological performance between the contacting surfaces of the tool material and the workpiece material. However, a suitable type of solid film must be chosen for the contacting surfaces of the mating materials since the coating of solid film on the tool surface is considered to be a high production cost, especially when the film type is chosen incorrectly. It is not possible to solve the tribological problem between the contacting surfaces of the mating materials, although DLC film has been reported to have superior performance in preventing adhesion of stainless steel. However, the study results obtained from the tribological simulation still lack the link between behavior and the real forming process. Therefore, the objective of this study is aimed at linking the results of the study of tribological behavior between the contacting surfaces of non-coated and coated tools in the forming of stainless steel by showing the simulating testing with the methods according to ASTM standards, which is considered as a means to help study the tribological methods in terms of economics. The results of the study will then be compared with the real deep drawing experiment.

\section{MATERIALS AND METHODOLOGY}

\section{Materials}

Cold work tool steel graded SKD11 is commonly used as the material for sheet metal forming tools. It is used as a raw material for tool making. The workpiece material is austenitic stainless steel SUS304 BA (bright annealed), with a thickness of $0.2 \mu \mathrm{m}$. The initial surface roughness $\mathrm{Ra}$ is $0.05 \mu \mathrm{m}$. The mechanical properties of the workpiece material obtained from tensile tests are in accordance with ASTM E8 [14]. The elemental composition is obtained from the optical emission spectroscopy (OES) technique. The mechanical properties of the workpiece material and the elemental composition of the tool material and workpiece material are shown in Table 1. 
Table 1: Mechanical Properties and Chemical Composition of the Studied Materials

\begin{tabular}{|c|c|c|c|c|c|c|c|c|}
\hline Symbol [JIS] & \multicolumn{3}{|c|}{ Tensile strength $\left[\mathrm{N} / \mathrm{mm}^{2}\right]$} & \multicolumn{3}{|c|}{ Tensile strength $\left[\mathrm{N} / \mathrm{mm}^{2}\right]$} & \multicolumn{2}{|c|}{ Elongation [\%] } \\
\hline \multirow{6}{*}{ SUS304 BA } & \multicolumn{3}{|c|}{711} & \multicolumn{3}{|c|}{267} & \multicolumn{2}{|c|}{62} \\
\hline & \multicolumn{8}{|c|}{ Chemical Composition [\%] } \\
\hline & $\mathrm{C}$ & $\mathrm{Si}$ & $\mathrm{Mn}$ & $\mathrm{P}$ & $\mathrm{S}$ & $\mathrm{Cr}$ & Mo & $\mathrm{Ni}$ \\
\hline & 0.0342 & 0.5467 & 1.0501 & 0.0361 & 0.0082 & 18.4744 & 0.1023 & 8.2941 \\
\hline & $\mathrm{Al}$ & $\mathrm{Cu}$ & $\mathrm{Nb}$ & $\mathrm{Ti}$ & $\mathrm{V}$ & $\mathrm{B}$ & $\mathrm{Fe}$ & \\
\hline & 0.0033 & 0.1417 & $<0.0002$ & 0.0017 & 0.0830 & $<0.0001$ & Bal. & \\
\hline \multirow{5}{*}{ SKD11 } & \multicolumn{8}{|c|}{ Chemical Composition [\%] } \\
\hline & $\mathrm{C}$ & $\mathrm{Si}$ & $\mathrm{Mn}$ & $\mathrm{P}$ & $\mathrm{S}$ & $\mathrm{Cr}$ & Mo & $\mathrm{Ni}$ \\
\hline & 1.4346 & 0.2285 & 0.2869 & 0.0337 & 0.0028 & 11.6004 & 0.8489 & 0.4832 \\
\hline & $\mathrm{Al}$ & $\mathrm{Cu}$ & $\mathrm{Nb}$ & $\mathrm{Ti}$ & $\mathrm{V}$ & B & $\mathrm{Fe}$ & \\
\hline & 0.0067 & 0.1656 & - & - & 0.2421 & - & Bal. & \\
\hline
\end{tabular}

\section{Deep Drawing Testing}

The deep drawing experiment of stainless steel sheets is made by the cylindrical cup deep drawing die by the $800 \mathrm{kN}$ hydraulic press. The forming force and punch displacement are measured by a load cell and linear variable differential transformer (LVDT). Data from both measuring devices are converted from analog signal to digital signal by an EDX-100 Kyowa data logger. The deep drawing die set installation with LVDT and force measuring device are shown in Figure 1.

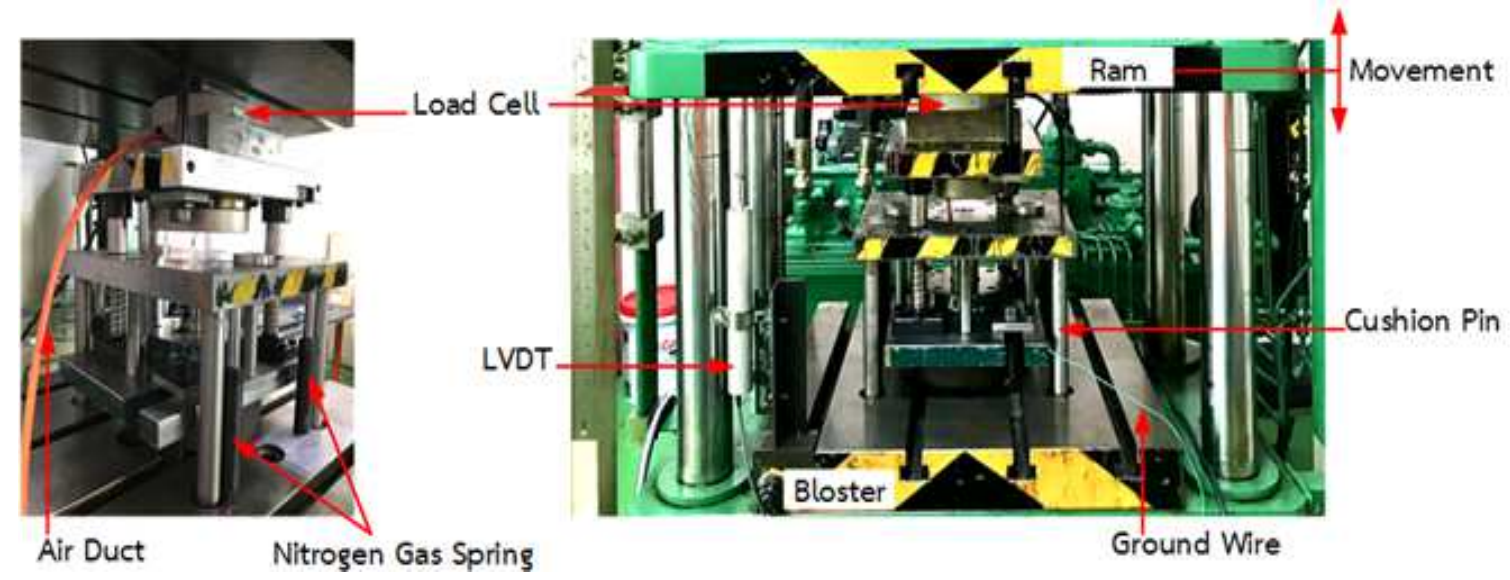

Figure 1: Deep Drawing Die Set and Measuring Device Setup.

The deep drawing process parameters are listed in Table 2. The punch, die and blank holder are made from SKD11 tool steel, hardened to a hardness range of $60 \pm 2 \mathrm{HRC}$. The surface roughness of these parts is controlled to have an average surface roughness Ra of $0.1 \pm 0.05 \mu \mathrm{m}$, both of which are commonly used for cold forming operations [3,15-17]. The blank holder force is $8 \mathrm{kN}$, providing a constant force with nitrogen gas springs. The tests were conducted by using a deep drawing die with and without lubricants. The studied solid films in this work are DLC film and TiAlN film. The film thickness is obtained by cross-section measurement of each type of film coated on hardened tool steel through scanning electron microscopy (SEM). To reduce the effect of the substrate's hardness, the film hardness was examined by using a HYSITRON nano-mechanical testing instrument by a Berkovich indenter indented on the film surface with an incremental force of $0-1000 \mu \mathrm{N}$ and processing with TriboScope software. The surface roughness of the solid film and substrate were measured by the stylus roughness tester with a test distance of $8.6 \mathrm{~mm}$ with a cut-off length of $0.8 \mathrm{~mm}$. The results of the film testing are shown in Table 3. 
Table 2: Deep Drawing Experimental Conditions

\begin{tabular}{|l|c|}
\hline \multicolumn{1}{|c|}{ Item } & Value \\
\hline Punch diameter $[\mathrm{mm}]$ & 32.00 \\
\hline Die diameter $[\mathrm{mm}]$ & 32.05 \\
\hline Punch corner radius $[\mathrm{mm}]$ & 2.80 \\
\hline Die corner radius $[\mathrm{mm}]$ & 1.50 \\
\hline Punch speed $[\mathrm{mm} / \mathrm{sec}]$ & 7.00 \\
\hline Blank holder force $[\mathrm{kN}]$ & $8.00($ Constant $)$ \\
\hline Deep drawing ratio & 1.70 \\
\hline Lubrication & $\begin{array}{c}\text { LUBETECH G-3153 stamping oil } \\
\text { Viscosity } 53.73 \mathrm{~mm} / \mathrm{s}^{2}\left(40^{\circ} \mathrm{C}\right)\end{array}$ \\
\hline Dry condition & Acetone cleaning \\
\hline
\end{tabular}

Table 3: Physical and Hardness Properties of Film Coatings and SKD11 Substrate

\begin{tabular}{|c|c|c|c|c|}
\hline Film Type & Color & Film Thickness $[\mu \mathrm{m}]$ & Surface Roughness: Ra [ $\mu \mathrm{m}]$ & $\begin{array}{c}\text { Hardness } \\
\text { [HV] }\end{array}$ \\
\hline DLC & Silver back & 1.20 & 0.079 & 2993 \\
\hline TiAlN & Purple & 2.69 & 0.106 & 2762 \\
\hline \multicolumn{3}{|c|}{ Non-coated die (Hardened SKD11) } & 0.114 & 714 \\
\hline
\end{tabular}

\section{Tribological Simulation Testing}

An Anton Paar tribometer is used to study the tribological properties between the contacting surfaces of the tool and workpiece material by using the pin-on-disk method according to ASTM G99-95 [18]. Hardened SKD11 balls of 6 mm in diameter were held by the ball holder instead of the pin for pin-on-disk testing. The disk was prepared to be $30 \mathrm{~mm}$ in diameter from the SUS304 BA stainless steel by electro-discharge machining (EDM) to prevent deflection. The test was conducted in a control room at a temperature and relative humidity equal to $25{ }^{\circ} \mathrm{C}$ and $60 \pm 3 \%$, respectively. In the case of dry conditions, the ball and disk were cleaned before testing by using acetone with ultrasonic equipment for 2 minutes to ensure that the test is under dry conditions. The test conditions are in accordance with the deep drawing experiment with a sliding speed of $7 \mathrm{~mm} / \mathrm{s}$.

The normal load used in the test is estimated from the deep drawing simulation using a finite element method under the same conditions as the deep drawing experiment to find the maximum contact pressure between the contacting surfaces of tool and workpieces while forming. From the deep drawing simulation, the maximum contact pressure is 635 $\mathrm{MPa}$. When using the Hertzian equation [19], a normal load of $1 \mathrm{~N}$ is used in comparison with the deep drawing experiment. The friction coefficient between the contacting surfaces can be obtained from InstrumX software version 7.0.10, which is connected to the tribometer. The reported value is the mean value of the friction coefficient which is tested under the sliding distance of $50 \mathrm{~m}$. At every sliding distance of $50 \mathrm{~m}$ to a sliding distance of $1200 \mathrm{~m}$, the ball will be expanded to examine the surface damage characteristics with a Mitutoyo Vision Unit microscope to photograph and measure the wear track, as shown in Figure 2. Ball wear can be calculated by Equation 1.

$$
V=\pi h^{2}\left(r-\frac{h}{3}\right)
$$

Where $V=$ wear volume $\left(\mathrm{mm}^{3}\right)$,

$h=$ distance from the arc of the ball to the wear scar $(\mathrm{mm})$,

$r=$ ball radius $(\mathrm{mm})$ 


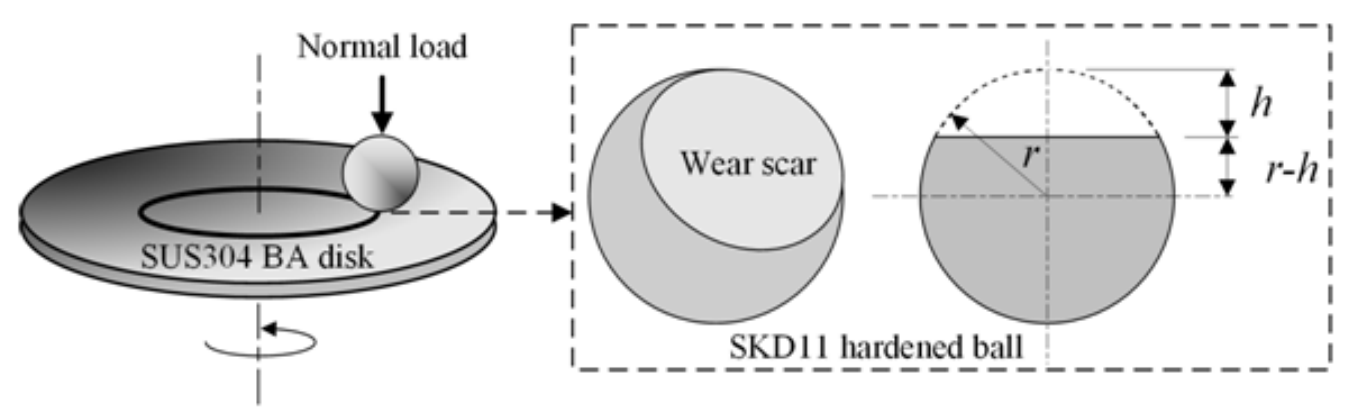

Figure 2: Illustration of Simulation Testing and Schematic Diagram of Worn Ball.

\section{RESULTS AND DISCUSSION}

\section{Tribological Property Investigation}

From the simulation testing by using a tribometer, the tribological behavior of the contacting surfaces between the SUS304 BA stainless steel and various tool materials under studied conditions are demonstrated with a graph of the friction coefficient by the sliding distance as shown in Figure 3 .

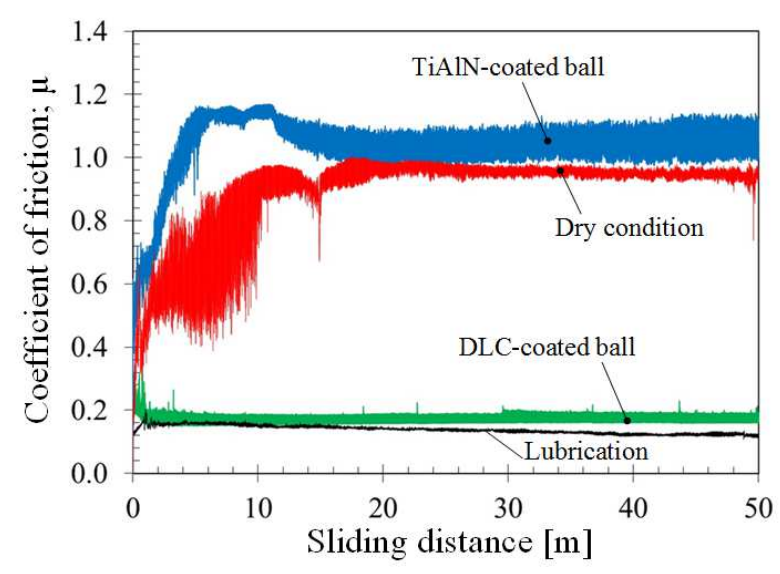

Figure 3: Friction Coefficient of Mating Materials.

It is well known that the use of lubricants can help to reduce friction between the contacting surfaces of mating materials. The performance depends on the type of lubricant and the surface of the mating material $[1,5,6,13]$. From the pin-on-disk test, the friction coefficient between the surfaces of the hardened SKD11 tool material and SUS304 BA austenitic stainless steel under lubricated conditions has average value that is 6 times smaller. The DLC film showed performance when sliding relative to SUS304 BA stainless steel when considering the friction coefficient between the contacting surfaces under sliding without using lubricants. This is approximately the same as that of a non-coated ball under testing using a lubricant while the film with high surface roughness as TiAlN gave the highest average friction coefficient value when sliding relative to SUS304 BA stainless steel under dry conditions. 


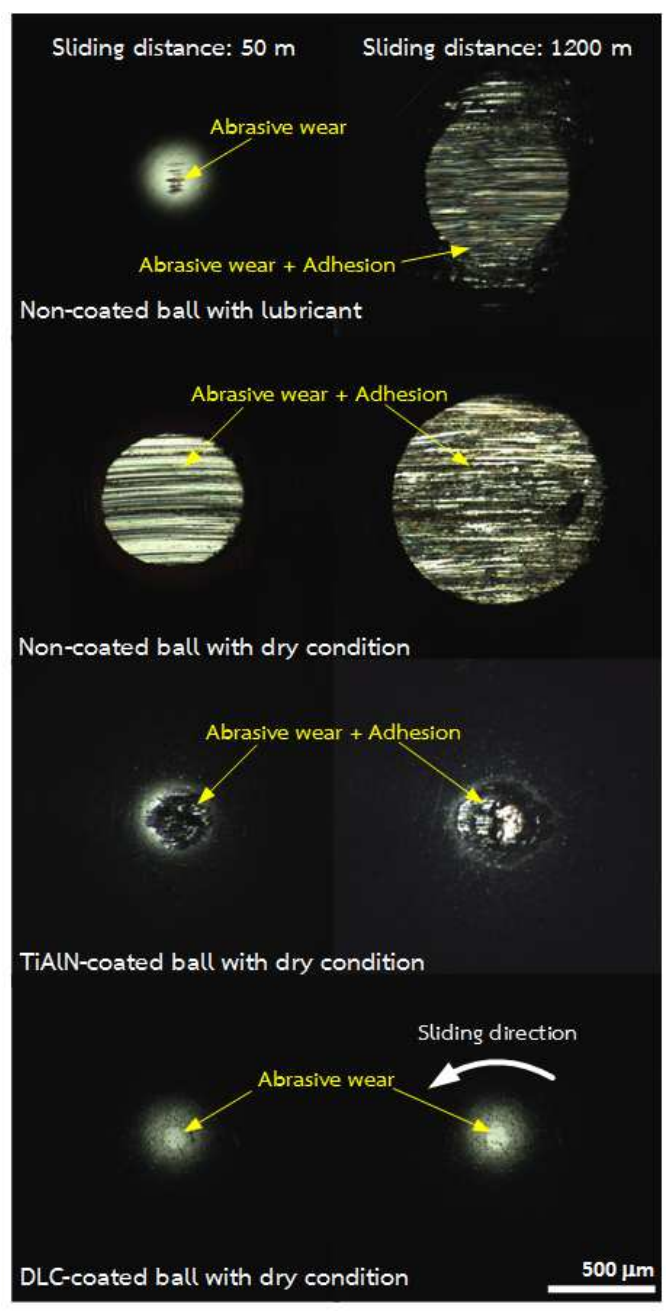

Figure 4: Failure Modes of Ball Specimen.

When examining the damage of the tool material as in Figure 4, it was found that the high hardness DLC film has good tribological performance when sliding relative to stainless steel, even in dry conditions. It can be considered by the dimension of the wear track on the surface of the DLC-coated ball, which is the smallest. Also, there was no adhesion on the surface of the ball, even after $1200 \mathrm{~m}$. However, other test conditions show the failure mode of abrasive wear combined with the adhesion of the workpiece material on the ball surface. Although the TiAlN film is found with damage and adhesion on the tool material, the advantage of the film's hardness can prevent the tool material from wear as shown in the results of measuring the wear volume of the ball in Figure 5. The TiAlN-coated ball has lower average wear volume compared to the non-coated ball in both lubricated and dry conditions. Wear behavior of hardened SKD11 tool steel with a solid film coating will be in the form of high wear volume at the first stage, and after that the performance of the film will prevent the wear of the tool material by observing the low slope graph in the first stage of the wear volume graph. However, in the case of the non-coated ball, the wear volume will increase continuously in terms of sliding distance. DLC film with high hardness, low surface roughness and a low friction coefficient demonstrates the anti-wear performance of the tool materials even when operating under dry conditions. 


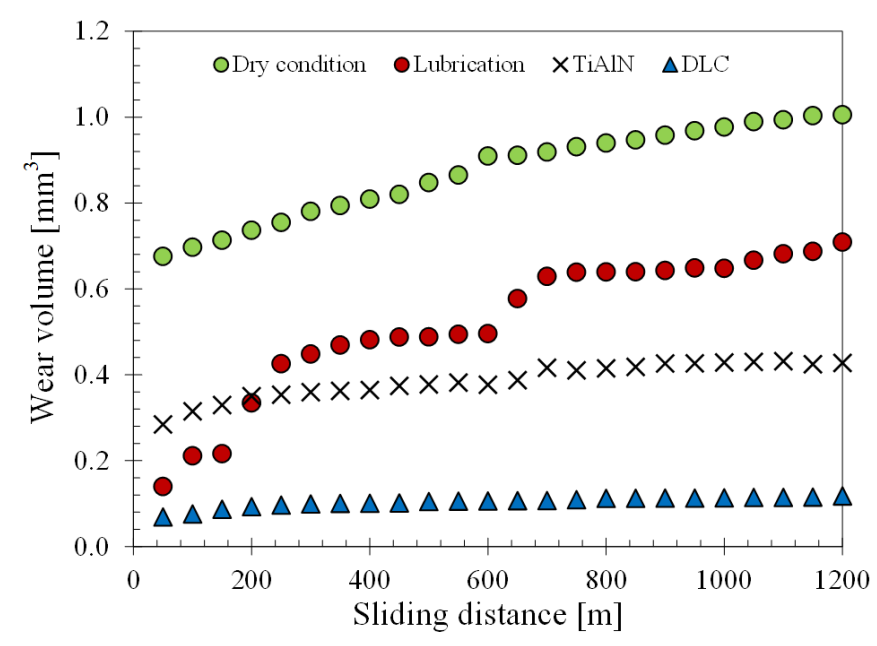

Figure 5: Wear Volume of Ball Specimen.

\section{Deep Drawing Experiment}

The results of the deep drawing of SUS304 BA stainless steel under the same deep drawing process parameters but with different tribological conditions show that the deep drawing die coated with TiAlN film cannot form SUS304 BA stainless steel for even one successful cup, due to the breakage of the stainless steel sheet during forming under dry conditions. When experimenting with lubricants, stainless steel sheets also cannot be formed, and the damage observed is the same as when lubricants are not used. While the hardened SKD11 cold work tool steel die was able to form stainless steel sheet workpieces into a successful cup over 130 times under dry conditions, a fractured cup was found thereafter. When using lubricant to help in forming, the hardened SKD11 die can successfully form a cup more than 10 times in comparison to the case with dry conditions. The hardened SKD11 die coated with DLC film demonstrates the tribological performance properties over SUS304 BA stainless steel. It is capable of successfully forming stainless steels cups more than 1500 times under dry conditions. The workpiece characteristics obtained by deep drawing under various tribological conditions is shown in Figure 6.

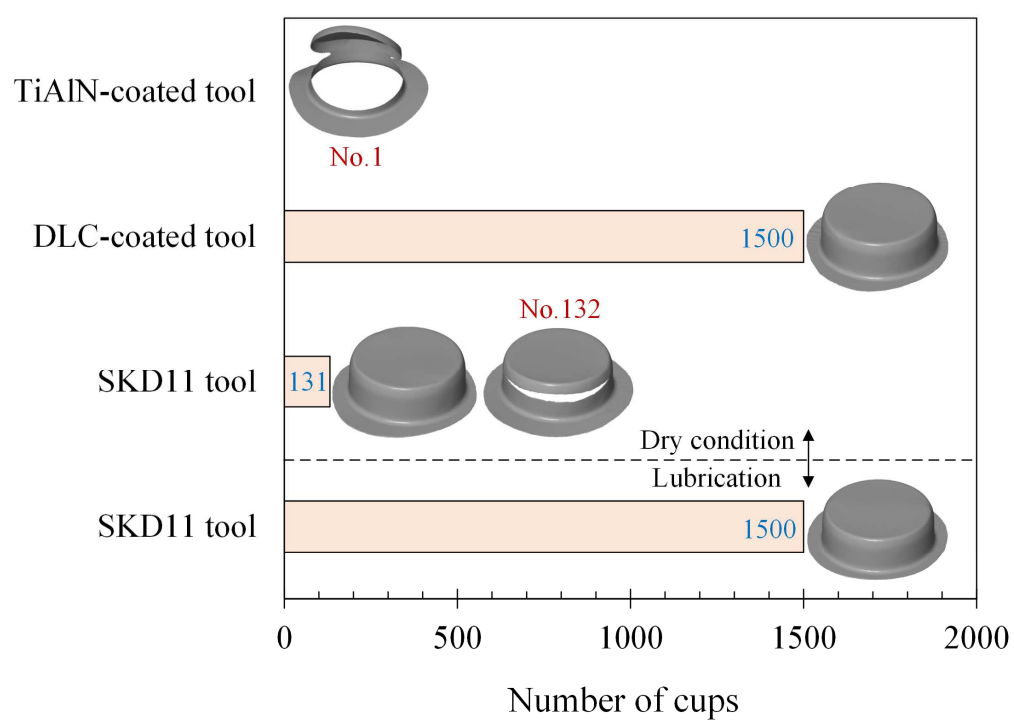

Figure 6: Number of Deep Drawing. 


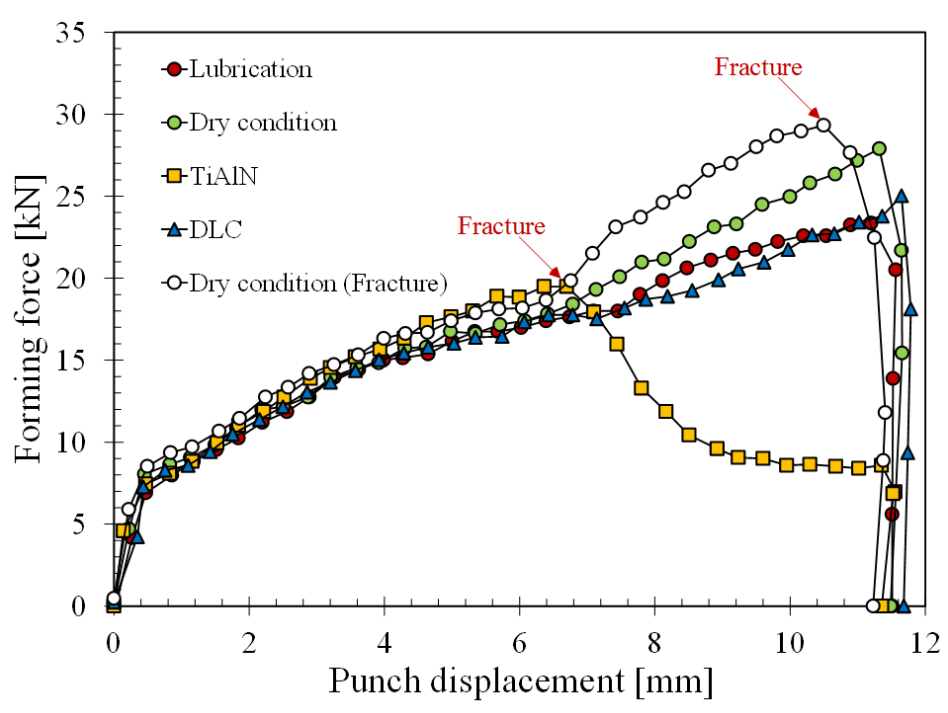

Figure 7: The Forming Force Versus Punch Displacement Diagram.

The deep drawing behavior was compared with the forming force (including constant blank holder force; $8 \mathrm{kN}$ ) versus the punch displacement as shown in Figure 7. When the punch touches the initial blank sheet and moves to draw the blank sheet through the die radius, the forming force value will increase rapidly in order to overcome the friction between the contacting surfaces of sheet metal and the blank holder, and also the contacting surfaces of sheet metal and die. During this period, the blank sheet was bent with the punch corner radius and die corner radius causing the workpiece to permanently deform into the corner of the cup. As the punch continues to move, the forming force still increases as the blank sheet was drawn through the die corner radius by the punch movement to create the sidewall of a cup. The forming force will increase when the punch displacement increases until the end of the forming stroke (11.5 mm). When the punch moves back to the starting position, the forming force will fall rapidly. For cases where the blank sheet has been damaged, at that location, the forming force graph will rapidly decrease, for example, the graphs of blank sheet that were formed by non-coated tool and TiAlN-coated tool under dry conditions.

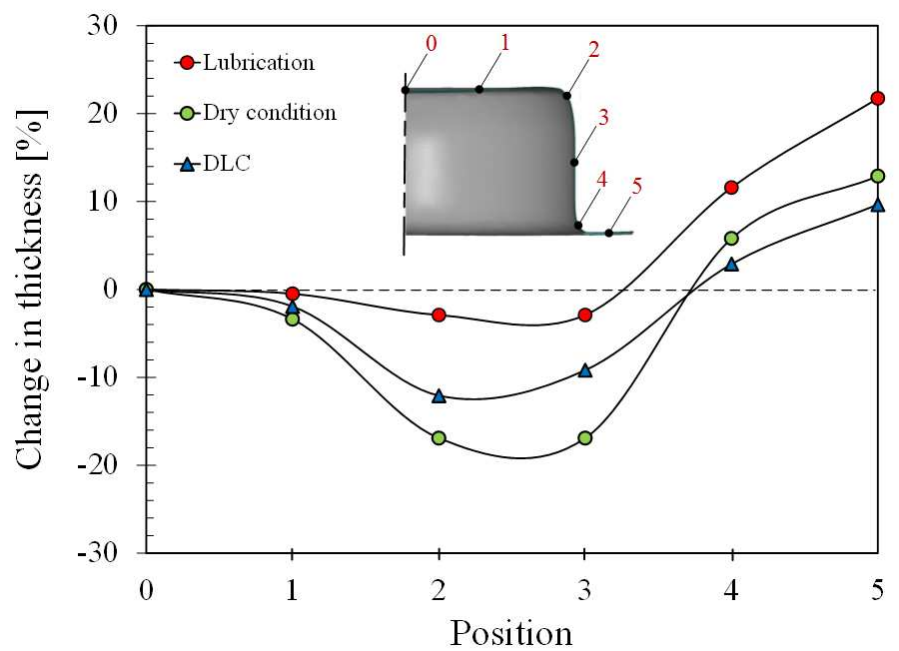

Figure 8: The Percentage of Change in Thickness of Deep Drawing Cup.

In general, the deep drawing process is assumed to have the thickness of the initial blank sheet, constant throughout the forming. However, in actual forming, the thickness of the sheet metal will vary from the initial thickness depending on the material flow during forming [1]. When examining the thickness of the first 30 deep drawn cups with the 
various tools which have different tribological properties, it was found that the cups obtained from each tribological condition had the thickness value of a blank sheet decreasing in various positions of the cup as seen in Figure 8. It is noticed that the cup formed by a non-coated tool under dry conditions will have a much lower thickness compared to the initial blank sheet thickness, especially in the area near the position of the fracturing of the sheet material.

Figure 9 shows the surface roughness of the SUS304 BA stainless steel cups that were drawn under various conditions. It seems that the surface roughness, $\mathrm{Ra}$ and $\mathrm{Rz}$ of the formed cups do not differ significantly. From previous studies [3,4,9-11], if there is adhesion of the workpiece material on the tool surface, it is a result of the roughness of the formed workpiece continually increasing. When observing the surface of deep drawing dies that were used to form SUS304 BA stainless steel sheet according to the number of cups as shown in Figure 6, it was found that no SUS304 BA stainless steel transferred or adhered onto the surface of the dies.

Based on the results of the tribological investigation and the deep drawing experiment, it was found that the different tribological properties between the contacting surfaces of the tooling material and the workpiece materials affects the formability and forming behavior differently. This can be seen from damage to the formed cup under the same forming process parameters. It seems that the roughness of the tooling affects the friction coefficient between the contacting surfaces of the mating materials, especially in the case of operation under dry conditions. The high friction will resist the flow of the sheet metal through the surface of the die and the blank holder. As the punch continued to move and draw the sheet material, it resulted in a change of thickness to the sheet metal. A large reduction in material thickness results in a high strain on the material, and if it exceeds the material constant value, the sheet material will fracture.

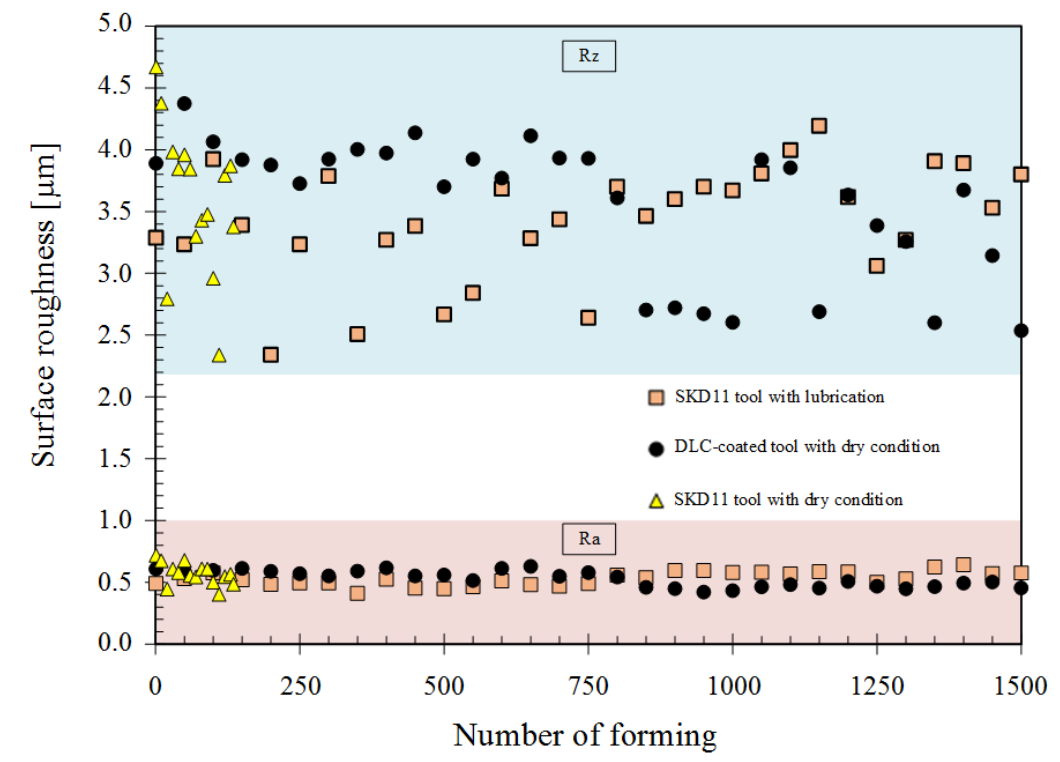

Figure 9: The Surface Roughness of Deep Drawing Cups with the Number of Forming.

Although the deep drawing experiment did not find the adhesion of SUS304 BA stainless steel on the tool surface under some conditions, the stainless steel was torn first or was still in the working range, where the lubricant and solid film are still effective at preventing adhesion of the workpiece material particles. However, the simulation testing by tribometer demonstrates the adhesion problems of SUS 304 BA stainless steel when relatively moving on the tool material. 


\section{CONCLUSIONS}

From the study of tribological effects in deep drawing operation of SUS304 BA stainless steel, the results are concluded as follows:

- Lubricant can reduce the friction coefficient between the contacting surfaces of the hardened SKD11 tool material and SUS304 BA stainless steel more than 6 times.

- The hardness of solid film is advantageous for reducing the wear volume of hardened SKD11 tool materials when relatively sliding on SUS304 BA stainless steel.

- The hardened SKD11 tool with TiAIN coating cannot deep draw SUS304 BA stainless steel, while the hardened SKD11 tool can deep draw 131 successful cups of SUS304 BA stainless steel under dry conditions.

- DLC film can improve the tribological properties between the contacting surfaces of the hardened SKD11 tool steel and SUS304 BA stainless steel, even when performing under dry conditions.

- Tribological properties between the contacting surfaces of the tool material and the workpiece material affect the formability of the workpiece material. The improvement of the tribological properties between the contacting surfaces of mating materials can help improve formability of sheet metal material.

\section{ACKNOWLEDGEMENTS}

The authors gratefully acknowledge the Faculty of Engineering, Srinakarinwirot University who provide a research grant from the 2019 annual income budget.

\section{REFERENCES}

1. K. Lange, (1985), Handbook of metal forming, McGraw-Hill, Inc.

2. F. Vollertsen, F. Schmidt, (2014), Dry metal forming: Definition chances and challenges, International Journal of Precision Engineering and Manufacturing-Green Technology, Vol. 1, No. 1, pp. 59-62.

3. M. Murakawa, N. Koga, T. Kumagai, (1995), Deep-drawing of aluminum sheets without lubricant by use of diamond-like carbon coated dies, Surface and Coatings Technology Vol. 76-77, pp. 553-558.

4. Jeewg, Muhsin J., Abdal-Kareem F. Hassan, and Jawad K. Zeboon. "Experimental and numerical investigation of the dynamic characteristic of laminated composite plate hybrid with steel." Int. J. of General Eng. and Techn.(IJGET) 3 (2014): 1.

5. S. Kataoka, M. Murakawa, T. Aizawa, H. Ike, (2004), Tribology of dry deep-drawing of various metal sheets with use of ceramics tools, Surface and Coatings Technology, Vol. 177-178, pp. 582-590.

6. Yun, Kyyoul, et al. "New Fabrication Method Suggestion of the Motor Core with Dissimilar Metal Bonding Method." IASET: International Journal of Metallurgical, Materials and Chemical Engineering (IASET: IJMMCE) 1. 3, Apr - May 2016; 1-8

7. B. Podgornik, S. Hogmark, O. Sandberg, (2004), Influence of surface roughness and coating type on the galling properties of coated forming tool steel, Surface and Coatings Technology, Vol. 184, pp. 338-348.

8. B. Podgornik, S. Hogmark, O. Sandberg, (2006), Proper coating selection for improved galling performance of forming tool steel, Wear, Vol. 261, pp. 15-21.

9. P. Karlsson, A. Gåård, P. Krakhmalev, (2014), Influence of tool steel microstructure on friction and initial material transfer, Wear, Vol. 319, pp. 12-18. 
10. Parthiban, A., et al. "Experimental Investigation of plasma arc cutting for stainless steel sheet, '." International journal of mechanical and production engineering research and development 8.1 (2018): 907-914.

11. Y. Abe, W. Daodon, N. Takahashi, K. Mori, (2016), Improvement of seizure resistance by roughening surface of stainless steel drawn cup in ironing using die having lubricant pockets, Production Engineering Research and Development, Vol.10, pp. $551-562$

12. Saravanan, S., M. Saravanan, and D. Jeyasimman. "Study on Effects of Spring Back on Sheet Metal Bending Using Simulation Methods." International Journal of Mechanical and Production Engineering Research and Development (IJMPERD), 8 (2), 923-932p (2018).

13. B. Sresomroeng, K. Lawanwong, V. Premanond, R. Hato, P. Kaewtatip, A. Khanchawana, N. Koga, (2009), Tribological behavior of thin film coatings against high strength steels, International Journal of Abrasive Technology, Vol. 2, No. 3, pp. $313-328$

14. B. Sresomroeng, V. Premanond, P. Kaewtatip, A. Khantachawana, N. Koga, S. Watanabe, (2010), Anti-adhesion performance of various nitride and DLC films against high strength steel in metal forming operation, Diamond \& Related Materials, Vol. 19, pp. 833-836.

15. B. Sresomroeng, V. Premanond, P. Kaewtatip, A. Khantachawana, A. Kurosawa, N. Koga, (2011), Performance of CrN radical nitrided tools on deep drawing of advanced high strength steel, Surface \& Coatings Technology, Vol. 205, pp. 41984204.

16. T. Horiuchi, S. Yoshihara, Y. Iriyama, (2012), Dry deep drawability of A5052 aluminum alloy sheet with DLC-coating, Wear, Vol. 286-287, pp. 79-83.

17. H. Kim, T. Altan, Q. Yan, (2009), Evaluation of stamping lubricants in forming advanced high strength steels (AHSS) using deep drawing and ironing tests, Journal of Materials Processing Technology, Vol. 209, pp. 4122-4133.

18. Standard Test Methods for Tension Testing of Metallic Materials, ASTM E8/E8M-13a, 2013.

19. T. Altan, S. Oh, H. Gegel, (1983), Metal forming: Fundamentals and applications, American Society for Metals.

20. V. Boljanovic, (2013), Sheet metal stamping dies: Die design and die-making practice, Industrial Press Inc.

21. Standard components for press dies 2007.9 - 2008.8 catalog, Misumi Corporation, 2008.

22. Standard Test Method for Wear Testing with a Pin-on-Disk Apparatus, ASTM G 99-95a, 2000.

23. B. Bhushan, (2001), Modern tribology handbook, CRC Press LLC.

\section{AUTHORS PROFILE}

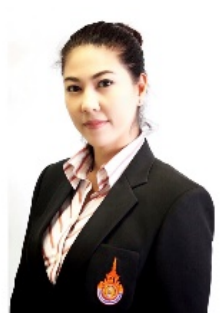

Natchanun Angsuseranee, received her M.Eng from Kasetsart University, Thailand. She is a head of Department of Manufacturing Engineering, Rajamangala University of Technology Suvarnabhumi, Thailand. Her research interests are metal forming, tribology and materials processing. 


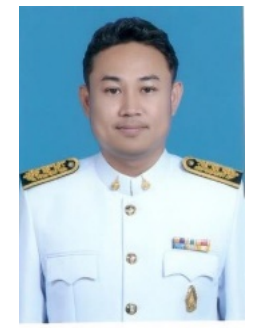

Bhadpiroon Watcharasresomroeng, has been working as a Lecturer at the Department of Tool and Die Engineering, Rajamangala University of Technology Suvarnabhumi, Thailand. He received a Doctor of Engineering (D.Eng.) in metal forming technology from the Department of Tool and Materials Engineering, King Mongkut's University of Technology Thonburi (KMUTT), Thailand. His research interests are metal forming processes and the relevant fields.

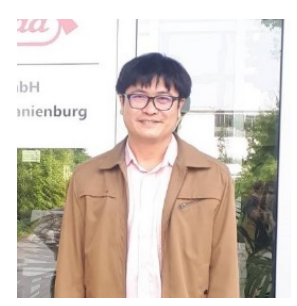

Pracha Bunyawanichakul, has been working as an Associate Professor at the Department of Mechanical Engineering, Srinakharinwirot University, Thailand. He received a Ph.D. in Mechanical Engineering from the University of Tasmania, Australia.

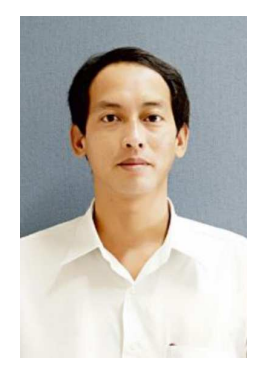

Siradej Chartniyom, has been working as an Assistant Professor at the Department of Industrial Engineering, Srinakharinwirot University, Thailand. He received a Ph.D. in Manufacturing Engineering from the University of South Australia, Australia. 